Review

\title{
Treating Traumatic Brain Injuries with Electroceuticals: Implications for the Neuroanatomy of Consciousness
}

\author{
Jihad Aburas ${ }^{1}$, Areej Aziz ${ }^{2}$, Maryam Butt ${ }^{2}$, Angela Leschinsky ${ }^{2}$ and Marsha L. Pierce ${ }^{1, *(D)}$ \\ 1 Department of Pharmacology, Midwestern University, Downers Grove, IL 60515, USA; \\ jabura@midwestern.edu \\ 2 Chicago College of Osteopathic Medicine, Midwestern University, Downers Grove, IL 60515, USA; \\ aaziz58@midwestern.edu (A.A.); Maryam.Butt@midwestern.edu (M.B.); \\ angela.leschinsky@midwestern.edu (A.L.) \\ * Correspondence: mpierc1@midwestern.edu; Tel.: +1-630-515-6068
}

check for updates

Citation: Aburas, J.; Aziz, A.; Butt, M.; Leschinsky, A.; Pierce, M.L. Treating Traumatic Brain Injuries with Electroceuticals: Implications for the Neuroanatomy of Consciousness. NeuroSci 2021, 2, 254-265. https:// doi.org/10.3390/neurosci2030018

Academic Editor: James Sonne

Received: 30 June 2021

Accepted: 24 July 2021

Published: 27 July 2021

Publisher's Note: MDPI stays neutral with regard to jurisdictional claims in published maps and institutional affiliations.

Copyright: (c) 2021 by the authors. Licensee MDPI, Basel, Switzerland. This article is an open access article distributed under the terms and conditions of the Creative Commons Attribution (CC BY) license (https:// creativecommons.org/licenses/by/ $4.0 /)$.
Abstract: According to the Centers for Disease Control and Prevention (CDC), traumatic brain injury (TBI) is the leading cause of loss of consciousness, long-term disability, and death in children and young adults (age 1 to 44). Currently, there are no United States Food and Drug Administration (FDA) approved pharmacological treatments for post-TBI regeneration and recovery, particularly related to permanent disability and level of consciousness. In some cases, long-term disorders of consciousness (DoC) exist, including the vegetative state/unresponsive wakefulness syndrome (VS/UWS) characterized by the exhibition of reflexive behaviors only or a minimally conscious state (MCS) with few purposeful movements and reflexive behaviors. Electroceuticals, including non-invasive brain stimulation (NIBS), vagus nerve stimulation (VNS), and deep brain stimulation (DBS) have proved efficacious in some patients with TBI and DoC. In this review, we examine how electroceuticals have improved our understanding of the neuroanatomy of consciousness. However, the level of improvements in general arousal or basic bodily and visual pursuit that constitute clinically meaningful recovery on the Coma Recovery Scale-Revised (CRS-R) remain undefined. Nevertheless, these advancements demonstrate the importance of the vagal nerve, thalamus, reticular activating system, and cortico-striatal-thalamic-cortical loop in the process of consciousness recovery.

Keywords: traumatic brain injury; disorders of consciousness; vegetative state; unresponsive wakefulness syndrome; minimally conscious state; non-invasive brain stimulation; vagus nerve stimulation; deep brain stimulation; Coma Recovery Scale-Revised

\section{Traumatic Brain Injury and Consciousness}

Traumatic brain injury (TBI) is defined as an injury caused by an external force that results in the disruption of normal brain function. In the United States, between 2016-2017, there were approximately 451,000 cases of TBI that resulted in hospitalization. The most common mechanisms of injury contributing to TBI were unintentional falls and motor vehicle crashes [1]. Following a severe TBI, disorders of consciousness (DoC) are common sequela $[2,3]$. Clinical features correlated with prognosis include age and severity of the TBI [2,4-7]. In several studies, there is an inverse correlation between the probability of recovering from a DoC and the duration after the injury $[5,6,8]$; however, some recovery has been observed in patients years after the initial injury [3,9]. The integrity and function of various neural structures and their relationship to consciousness are crucial for predicting outcomes and treating patients [10,11].

In this review, we define consciousness, severe DoCs, and describe clinical screening mechanisms and clinically relevant scoring systems utilized for diagnosing severe DoCs. Next, we address current pharmaceuticals and electroceuticals described in case studies and/or evaluated in clinical trials that are used to treat severe DoCs. Finally, we discuss how 
these advanced clinical scoring systems, pharmaceuticals, and electroceutical therapeutics have contributed to our knowledge of the neuroanatomy of consciousness.

\section{Consciousness}

Consciousness, in its most basic sense, is defined as being awake and responsive to stimuli. The systems in the brain responsible for consciousness mediate sensory, motor, memory, and emotional functions that give rise to one's perceptions and emotions [12,13]. Levels of consciousness are generally assessed via three parameters: alertness, awareness, and attention. Alertness requires function of the ascending reticular activating system (ARAS) circuit involved in the sleep-wakefulness cycle and enables the individual to be receptive to stimuli $[5,6,14]$. Awareness requires function of sensory and motor cortical regions and circuits to enable perception of and response to stimuli $[15,16]$. Attention requires those same circuits and regions plus processing in the frontoparietal cortex, amygdala, and hippocampus which give rise to perceptions and feelings experienced by the individual (Figure 1) [17].

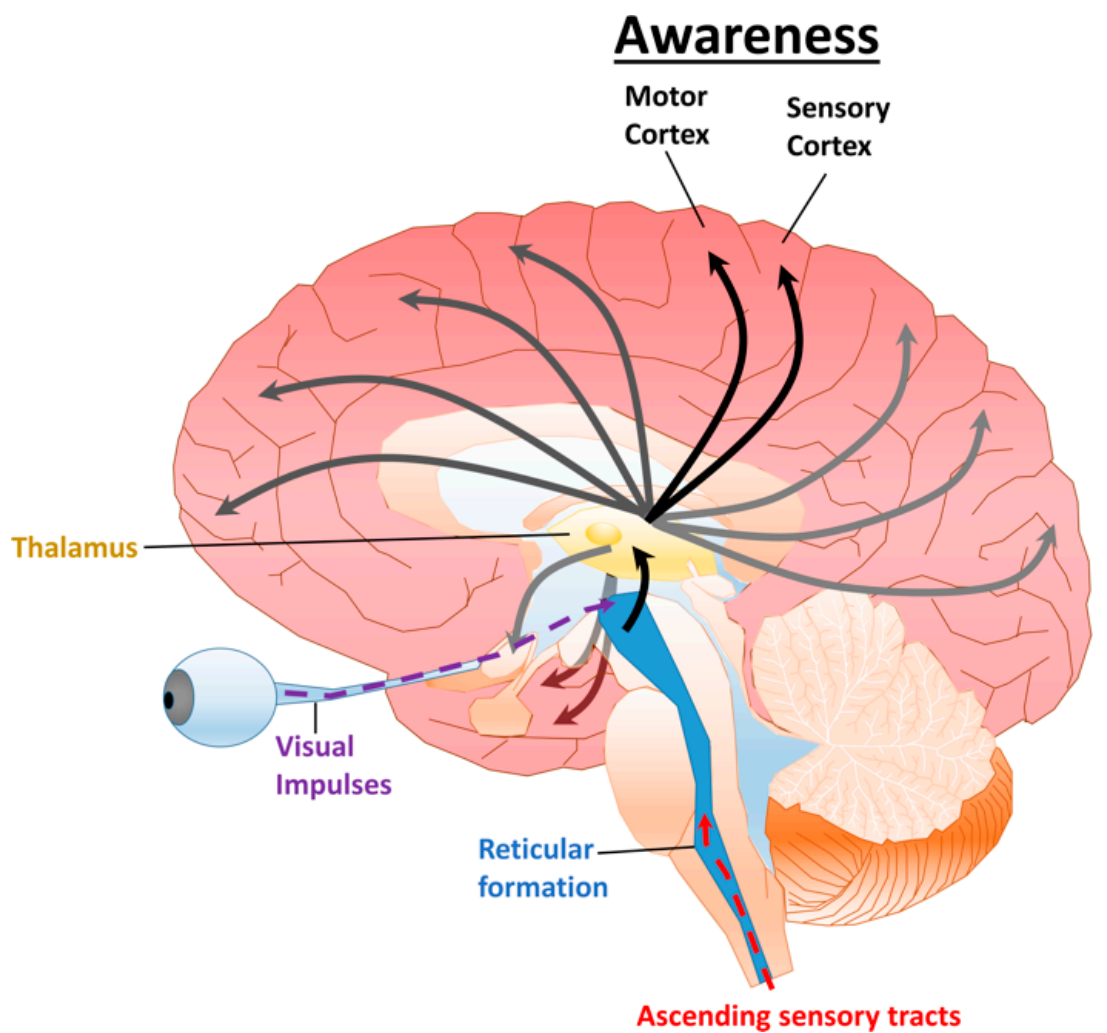

Figure 1. Diagram of the ARAS and cortical projections. The ARAS is composed of a network of neurons connecting the reticular formation, hypothalamus, and thalamus, which have widespread projections to various cortical regions. A variety of stimuli including visual and somatosensory (pain, touch, and temperature) excite the reticular activating system, generating arousal. Projections to the sensory and motor cortex are requisite for awareness. Additional connections to the frontoparietal cortex, amygdala, and hippocampus contribute to attention.

\subsection{Disorders of Consciousness}

Consciousness can be disrupted by pharmacological agents such as anesthetics or by brain injury. In both cases, there is a lack of subjective experience. Numerous etiologies can cause disorders of consciousness including: TBI, hypoxic-ischemic encephalopathy from cardiac arrest, ischemic stroke, hemorrhage (intracerebral, subdural, epidural, subarachnoid), seizures, toxic-metabolic insults, and metabolic abnormalities. Compared to TBIs, several of these etiologies including ischemic stroke and hypoxic-ischemic encephalopathy 
follow predictable patterns which allow for improved prognostication $[3,18]$. DoCs are generally classified as acute (within the first 28 days) or chronic (persistent) $[19,20]$.

Five levels of DoCs are generally used within the clinical setting: brain death, coma, vegetative state/unresponsive wakefulness syndrome (VS/UWS), minimally conscious state minus (MCS-), and minimally conscious state plus (MCS+) (Table 1). Accurate prognostication is crucial, because withdrawal of life-sustaining therapies is the leading cause of death for patients with acute TBI [21,22]. Both brain death and coma are acute diagnoses, with coma generally lasting no more than two to three weeks $[20,23]$. Brain death is the irreversible cessation of clinical brain functions, including the capacity to regulate respiratory and vegetative function, which is diagnosed using a series of tests known as the brain death examination. For children, this examination is performed twice before withdrawal of life sustaining therapies [23-25]. Coma is clinically defined as the complete absence of arousal or awareness [26], although some patients have described experienced awareness during the comatose state upon recovery. Unless the ARAS is severely injured, function generally returns within two to three weeks, at which time the vegetative systems that control the sleep-wake cycle, breathing, digestion, and basic motor reflexes begin functioning [27]. This clinical presentation is the VS/UWS, wherein the patient is alert but is not capable of attention or awareness [20]. Clinically, the VS/UWS is considered persistent one month after diagnosis [5-7]. Unlike coma and VS/UWS, the minimally conscious state (MCS) often includes impaired awareness and attention, as well as inconsistent responses that are consciously driven [9]. The first clinical signs to occur are generally visual pursuit and command following [11]. This category is further subdivided into without language (MCS-), or with language including command-following, intelligible verbalization, and/or intentional communication (MCS+) [4,28-30].

Table 1. Comparison of some clinical features in disorders of consciousness.

\begin{tabular}{|c|c|c|c|c|c|}
\hline DoC & Arousal & Awareness & Apnea & Eye Opening & Communication \\
\hline Brain Death & No & No & Artificial ventilation required & None & None \\
\hline Coma & ${ }^{\mathrm{a}} \mathrm{No}$ & ${ }^{b} \mathrm{No}$ & $\begin{array}{c}{ }^{\mathrm{C}} \text { Artificial ventilation } \\
\text { required }\end{array}$ & None & None \\
\hline VS/UWS & Yes & No & $\begin{array}{l}\mathrm{d} \text { Can breathe spontaneously } \\
\text { without assistance }\end{array}$ & Spontaneous & $\begin{array}{l}\text { Occasional moans } \\
\text { and grunts }\end{array}$ \\
\hline MCS- & Yes & Partial & $\begin{array}{l}\mathrm{d} \text { Can breathe spontaneously } \\
\text { without assistance }\end{array}$ & Spontaneous & $\begin{array}{l}\text { Occasional facial or } \\
\text { vocal activity }\end{array}$ \\
\hline MCS+ & Yes & Partial & $\begin{array}{c}{ }^{\mathrm{d}} \text { Can breathe spontaneously } \\
\text { without assistance }\end{array}$ & Spontaneous & $\begin{array}{l}\text { Some purposeful } \\
\text { facial or vocal } \\
\text { responses } \\
\text { (inconsistent) }\end{array}$ \\
\hline
\end{tabular}

${ }^{a}$ Vegetative responses may be elicited by stimuli. ${ }^{b}$ Comatose patients have occasionally noted being aware after recovery. ${ }^{c}$ Patients may make respiratory efforts. ${ }^{\mathrm{d}}$ Artificial ventilation may be used for support. Vegetative state/unresponsive wakefulness state (VS/UWS), minimally conscious state minus (MCS-), minimally conscious state plus (MCS+).

\subsection{Diagnosing Disorders of Consciousness}

Diagnosing DoCs after traumatic brain injury is crucial for appropriate treatment. The process begins with a standard neurological examination assessing consciousness; response to auditory, visual, and tactile stimulation; and assessment of pupillary and corneal reflexes. Additional clinical screens [31] can include computed tomography (CT) perfusion to assess brain death [23], diffusion tensor tractography (DTT) to evaluate the ARAS in the live human brain [32], functional magnetic resonance imaging (fMRI) and electroencephalography (EEG) responses to detect higher order cortical function [33-35], and positron emission tomography (PET) and fMRI to identify brain activity in individuals diagnosed as unresponsive $[19,36]$.

Several clinical scoring systems are used to determine levels of consciousness and disability (Table 2) [37]. The Coma Recovery Scale-Revised (CRS-R) is the gold-standard behavioral assessment, with a modified version for pediatric patients [38,39]. It consists of 
six categories that assess arousal as well as auditory, visual, motor, and communication functions. The score range is 0 to 23, with higher scores associated with higher function. Scores do not directly correspond to DoC diagnoses, but certain responses are associated with MCS-, MCS+, and emergence from MCS (Table 3) $[4,8,40]$. The Glasgow Coma Scale (GCS) is also used in a number of studies addressed in this review $[2,23,32,33]$. This scale consists of three components: eye opening, motor, and verbal responses with scores ranging from 3-15 (Table 2). There is substantial overlap in scores between DoCs, thus scores do not directly correspond to DoC diagnoses. A newer version, The Glasgow Outcome Scale Extended-Revised (GOSE-R) has been proposed to address difficulties in separating out MCS - and MCS+ [2,32,41]. Due to the time and training requirements for the CRS-R, the Simplified Evaluation of CONsciousness Disorders (SECONDs) was recently developed to provide a similar evaluation in $\sim 5 \mathrm{~min}$, which enables easy adaptation to emergency and critical care settings. SECONDs evaluates six mandatory items and two conditional items and provides a score ranging from 0-8 that corresponds with the patient's DoC diagnoses (Tables 2 and 3) [42,43]. The Disability Rating Scale (DRS) assesses eight items with scores ranging from 0-29, with 12-21 corresponding with MCS and 22-29 with VS/UWS and coma (Tables 2 and 3) $[2,4,9,29,44,45]$. Notably, there are numerous other assessments which evaluate similar properties not covered in this review [37].

Table 2. Select clinical scoring systems for determining levels of consciousness and disability.

\begin{tabular}{|c|c|c|}
\hline Clinical Scoring System & Category & Score Range \\
\hline \multirow{7}{*}{$\begin{array}{l}\text { Coma Recovery Scale-Revised } \\
\text { (CRS-R) }\end{array}$} & Auditory Function Scale & $0-4$ \\
\hline & Visual Function Scale & $0-5$ \\
\hline & Motor Function Scale & $0-6$ \\
\hline & Oromotor/Verbal Function Scale & $0-3$ \\
\hline & Communication Scale & $0-2$ \\
\hline & Arousal Scale & $0-3$ \\
\hline & Total Score & $0-23$ \\
\hline \multirow{4}{*}{ Glasgow Coma Scale (GCS) } & Eye Opening Response & $1-4$ \\
\hline & Verbal Response & $1-5$ \\
\hline & Motor Response & $1-6$ \\
\hline & Total Score & $3-15$ \\
\hline \multirow{9}{*}{$\begin{array}{l}\text { Simplified Evaluation of } \\
\text { CONsciousness Disorders } \\
\text { (SECONDs) }\end{array}$} & Observation & $0-1$ \\
\hline & Command-Following & $0-1$ \\
\hline & Visual Pursuit & $0-1$ \\
\hline & Visual Fixation & $0-1$ \\
\hline & Oriented Behaviors & $0-1$ \\
\hline & Arousal & $0-1$ \\
\hline & * Communication & $0-1$ \\
\hline & * Localization of Pain & $0-1$ \\
\hline & Total Score & $0-8$ \\
\hline \multirow{9}{*}{ Disability Rating Scale (DRS) } & Eye Opening & $0-3$ \\
\hline & Communication Ability & $0-4$ \\
\hline & Motor Response & $0-5$ \\
\hline & Feeding (Cognitive Ability Only) & $0-3$ \\
\hline & Toileting (Cognitive Ability Only) & $0-3$ \\
\hline & Grooming (Cognitive Ability Only) & $0-3$ \\
\hline & $\begin{array}{l}\text { Level of Functioning (Physical, } \\
\text { Mental,Emotional, Social) }\end{array}$ & $0-5$ \\
\hline & Employability & $0-3$ \\
\hline & Total Score & $0-29$ \\
\hline
\end{tabular}

* Conditional Items. 
Table 3. Clinical scoring system relation to DoC diagnoses.

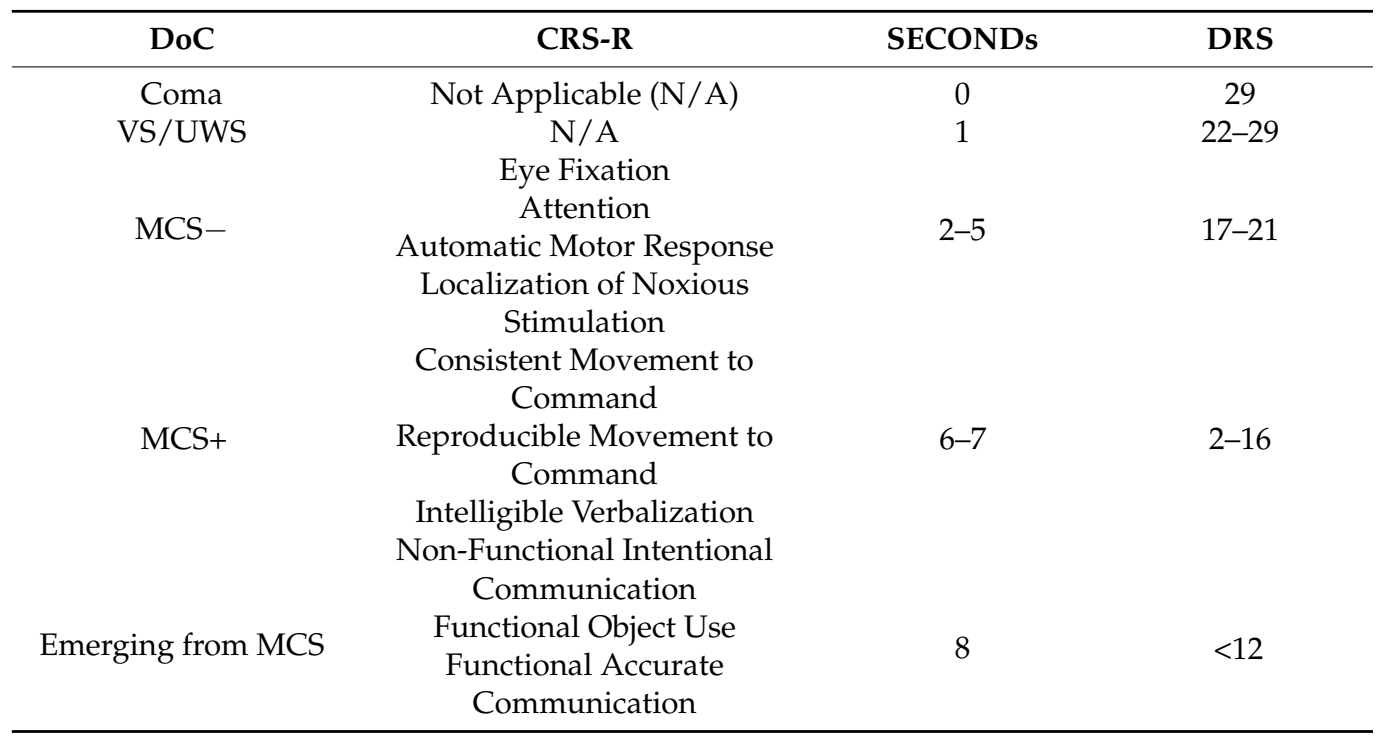

\section{Pharmaceuticals}

Currently, there are no United States Food and Drug Administration (FDA)-approved pharmaceuticals for the treatment of TBI. Pathologically, TBI follows a biphasic pattern consisting of the primary structural injury followed by a secondary injury cascade. Primary injuries include cerebral contusion, blood vessel damage, blood brain barrier disruption, axonal shearing, and neuronal apoptosis. The secondary injury cascade includes inflammation, edema, changes in cerebral circulation, glutamate toxicity, mitochondrial dysfunction, and increased reactive oxygen species (ROS) production. In 2019, the FDA fast-tracked NeuroSTAT (cyclosporine; NeuroVive Pharmaceutical) for the treatment of moderate-to-severe TBI by inhibiting mitochondrial permeability transition pore (mPTP), which is indicated in the secondary injury cascade [46]. Notably, if approved, this treatment will only be effective during the early acute injury phase. Amantadine is safe and has shown some accelerated recovery in studies of acute and subacute DoCs due to TBI [47-49], but with variable effectiveness [50,51]. Like amantadine, apomorphine has effects on the dopaminergic system. A case study and a pilot study with apomorphine described a spontaneous awakening phenomenon [52,53], and a controlled study has been proposed to evaluate its safety and effectiveness [54]. During the chronic phase post-TBI, case reports on zolpidem have indicated a paradoxical ability to improve consciousness [55,56]. An EEG study suggested it acts on cortical, striatal, and thalamic neuronal populations to potentially produce this spontaneous awakening phenomenon [57]. Controlled studies have shown zolpidem to be safe, but again showed variable effectiveness [58-61]. Lorazepam was also shown to be safe, albeit ineffective in a single study for TBI, but showed some effectiveness for patients with anoxic brain injury [61]. Together, these results suggest potential pharmaceutical options for acute, subacute, and chronic DoCs, with reasonable safety profiles but variable effectiveness.

\section{Electroceuticals}

Electroceuticals utilize electrical impulses, the nervous system's primary language, to treat disease. In general, electroceuticals consist of a power source that provides electrical stimulation to electrodes, which then deliver these impulses to targeted cells or tissues [62]. A number of electroceuticals currently have therapeutic uses including pacemakers; cochlear implants [63]; vagus nerve stimulation for treatment of epileptic seizures and depression [64]; and deep brain stimulation for Parkinson's disease, epilepsy, and other neurological disorders [65]. Although the first attempt at using electroceuticals to treat DoCs was in 1968 [66], progress was slow. With recent advances in imaging and 
assessment, a limited set of studies have evaluated electroceuticals for treating patients with TBI-induced DoCs [67].

\subsection{Non-Invasive Brain Stimulation}

Non-invasive brain stimulation (NIBS) utilizes an externally applied electrical current to stimulate brain activity. There are two main types of NIBS, transcranial direct current stimulation (tDCS) and transcranial magnetic stimulation (TMS). tDCS delivers a weak, continuous current flowing from an anode to a cathode (Figure 2A). One uncontrolled study showed improvements in the CRS-R up to a year after tDCS therapy [68], which was followed by similar improvements in a subgroup of patients using the CRS-R in a controlled double-blind study [69]. A retrospective analysis showed that tDCS responsive patients show preserved gray matter and metabolic activity in the dorso-lateral prefrontal cortex, medial-prefrontal cortex, precuneus, and thalamus, which are all areas involved in consciousness [70]. These improvements with tDCS were not consistent across all studies [71,72]. TMS delivers magnetic impulses generated by the flow of current through a coil placed on the scalp (Figure 2B). In DoCs, TMS has been used for assessing levels of consciousness [73]. Repetitive TMS (rTMS) has shown minor EEG changes and a single case report of behavioral improvement [74]. Similar improvements were also observed in a pilot trial in patients with chronic DoCs treated with rTMS and amantadine [75]. The most significant adverse effect associated with rTMS is induction of seizures [76]. Importantly, a study showed that tDCS and TMS are safe and well-tolerated in children with TBI [77].

\subsection{Vagus Nerve Stimulation}

The vagus nerve is comprised of autonomic sensory and motor fibers that control some motor movements in the mouth, the gag reflex, heart rate, and gastrointestinal peristalsis. Vagus nerve stimulation (VNS) utilizes a device surgically implanted under the skin (generally on the chest), and the electrode is threaded up connecting to the left vagus nerve (Figure 2C). Notably, the right vagus nerve is not utilized because of autonomic connections to the heart. One case study demonstrated CRS-R improvements from VS/UWS to MCS 15 years post-severe TBI [78]. A study utilizing non-invasive transcutaneous VNS (tVNS) was safe but showed few clinically relevant effects [79].

\subsection{Deep Brain Stimulation}

Deep brain stimulation (DBS) utilizes electrodes implanted into subcortical areas of the brain that are controlled by a pacemaker-like device surgically implanted under the skin (generally on the chest; Figure 2D). DBS procedures have utilized a number of different electrode placements, all of which correspond anatomically with projections of the ARAS [67]. Two out of five patients showed improvements following DBS therapy, with the responding patients showing an increase in medial cortex activity [80]. Although promising results have been seen in a number of small uncontrolled studies, controlled and randomized studies are necessary to determine therapeutic response to DBS in DoC following TBI [81]. Spontaneous recovery from TBI-induced DoCs generally occurs within the first 12 months post-TBI [5,6]. However, DBS therapy outcomes are often confounded by overlap in the timeframe for spontaneous recovery from DoCs, as well as a lack of controlled and randomized studies [82]. Recently, a DBS device was developed that can also continuously record electrophysiological responses to track objective effects in the patient rather than just correlating with the patient's subjective experience [65]. 
A

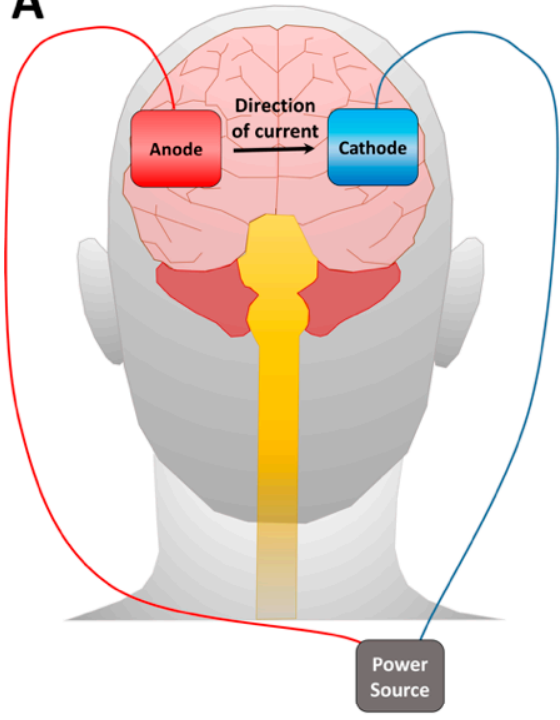

C

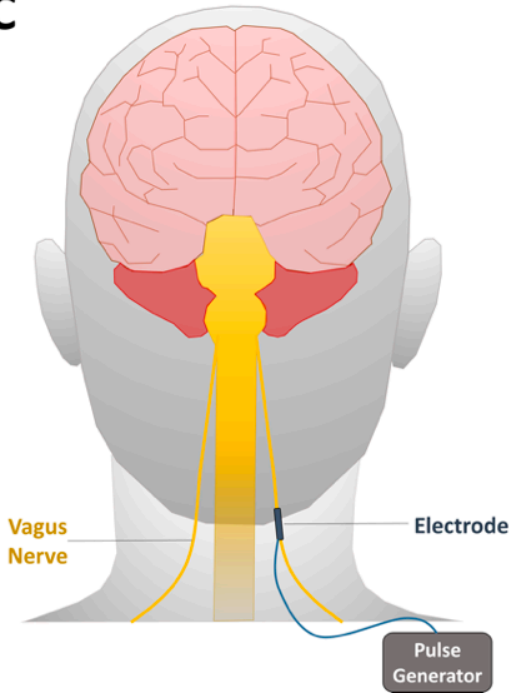

B

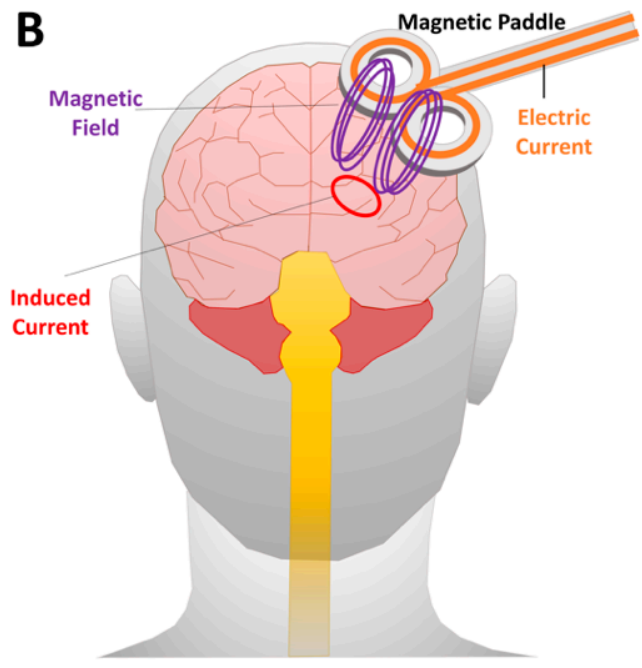

D

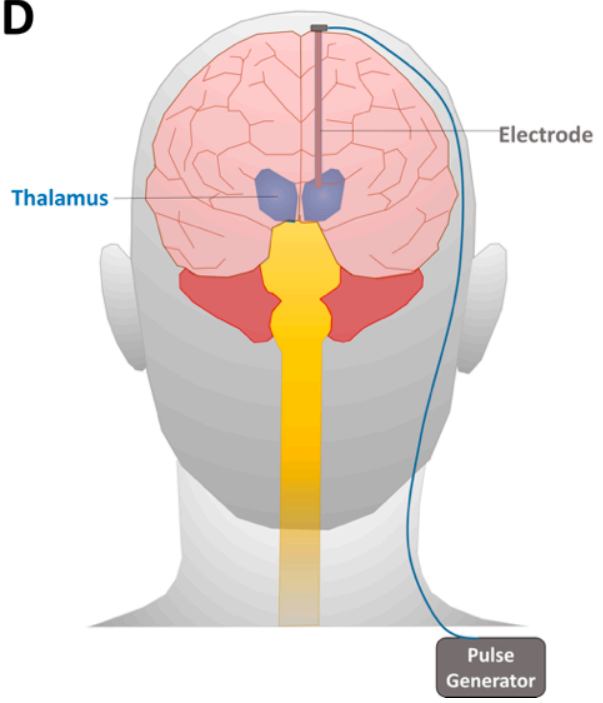

Figure 2. Diagram of electroceuticals used in patients with severe DoCs. (A) tDCS utilizes two electrodes that are placed on the scalp (an anode and a cathode) that are connected via wires to a power supply. Together, this makes a complete circuit through which a constant, low (1-2 milliampere; mA), electrical current is delivered for a set amount of time. (B) rTMS utilizes the flow of electric current through a magnetic coil placed over the scalp, generating a rapidly changing magnetic field that induces an electrical current. (C) VNS employs a pulse generator implanted under the skin that is connected by a wire to an electrode that is on the left vagus nerve. (D) DBS employs a pulse generator implanted under the skin that is connected by a wire to an electrode generally implanted into the thalamus.

\section{Neuroanatomy of Consciousness}

The neuroanatomy of consciousness is comprised of cortical and subcortical networks that enable alertness, awareness, and attention. The ARAS connects the reticular formation with thalamic nuclei, hypothalamus, and cerebral cortex. These connections control the sleep-wakefulness cycle and are considered a core component of consciousness [32], which is why the thalamus / ARAS is a primary target for DBS [67]. Following severe TBI, neuronal loss in the central thalamic nuclei is associated with coma, MCS, and VS/UWS diagnoses $[15,16,83,84]$. Ascending projections to the central thalamic nuclei play important roles in the sleep-wakefulness system as well as the cholinergic, serotonergic and noradrenergic arousal systems of the brainstem. Descending projections connect from 
frontal cortical regions to the central thalamic nuclei $[15,85]$. Interestingly, cerebral glucose metabolism can be used to differentiate MCS - and MCS+ patients, with MCS+ patients showing higher metabolism in left cortical areas crucial for language as well as in the posterior parietal, sensorimotor, premotor, and pre-supplementary motor cortices [30], some of which have direct cortico-thalamic projections from the central thalamus [16]. Projections from the central thalamus also innervate the striatum (caudate, putamen, and nucleus accumbens) and project onto medium spiny neurons [86], which are sensitive to dopamine deficiency [87], and may contribute to positive results seen with amantadine [47-49,75] and apomorphine $[52,53]$. Medium spiny neurons normally function to dis-inhibit the central thalamus by inhibiting the globus pallidus internus. This circuit is interrupted by severe TBI, resulting in lower output from the central thalamus. Inhibition of the globus pallidus internus by zolpidem may result in a more normal function of the central thalamus and thus explain the paradoxical observation with zolpidem treatment resulting in spontaneous awakenings [15,55,57-61] (Figure 3).

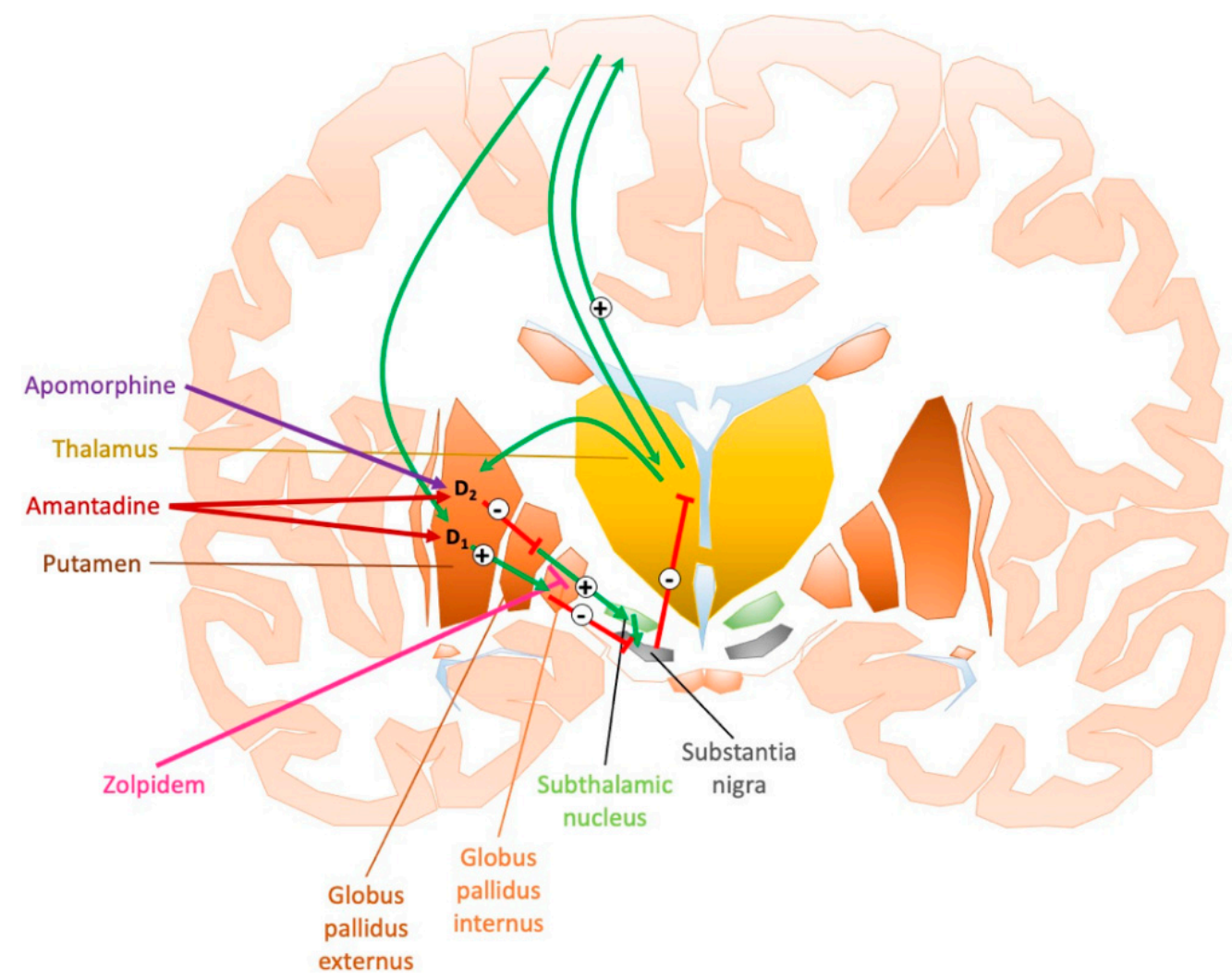

Figure 3. Diagram of the cortico-striatal-thalamic-cortical loop and potential impacts of apomorphine, amantadine, and zolpidem on spontaneous awakenings. There are two dopaminergic pathways in this loop, the direct pathway and the indirect pathway. The direct pathway expresses excitatory dopamine receptor $1\left(D_{1}\right)$, and striatal neurons project to the globus pallidus internus and then to the substantia nigra pars reticulata, which then inhibits the thalamus through GABAergic projections. The indirect pathway expresses the inhibitory dopamine receptor $2\left(D_{2}\right)$, and these striatal neurons project to the globus pallidus externus and then to the subthalamic nucleus. Glutamatergic neurons from the subthalamic nucleus project to the substantia nigra, which then inhibits the thalamus via GABAergic projections [88]. Amantadine is an indirect dopamine agonist and may contribute to both the direct and indirect pathways [48]. Apomorphine is a dopamine agonist with a high affinity for D2 receptors, feeding into the indirect pathway [54]. Zolpidem is a GABA agonist and may inhibit the GABAergic projections reducing inhibitory tone to hypoactive areas of the brain and enhancing thalamocortical pathways [57,60], Dopamine Receptor $1\left(D_{1}\right)$ and Dopamine Receptor $2\left(D_{2}\right)$. 


\section{Conclusions}

Since the first DBS therapy for TBI was attempted over 50 years ago [66], major advancements in diagnosing and imaging have improved clinical identification of brain activity that informs our understanding of the neuroanatomy of consciousness $[28,33,34,37,43]$. Likewise, recent studies using electroceuticals, pharmaceuticals, or both are now evaluated with our improved diagnostics and imaging $[36,47-49,59,68,71,78]$. Results of these studies have built upon our early understanding of the neuroanatomical structures and circuits involved in consciousness by identifying intact brain structures and their relation to DoC diagnoses and mechanisms of recovery $[15,16,27]$. However, small sample size, lack of appropriate controls, and therapeutics within the window of spontaneous recovery confound study interpretations $[67,81,82]$. Nevertheless, evidence is accumulating for recovery years after TBI-induced DoCs [3,9]. These advances emphasize the importance of diagnostic, therapeutic, and prognostic approaches to aid recovery in patients with TBI-induced DoCs.

Author Contributions: Conceptualization, M.L.P. and J.A.; writing-original draft preparation, M.L.P.; writing—review and editing, J.A., A.A., M.B. and A.L.; visualization, J.A., A.A., M.B., A.L. and M.L.P. All authors have read and agreed to the published version of the manuscript.

Funding: This research received no external funding.

Institutional Review Board Statement: Not applicable.

Informed Consent Statement: Not applicable.

Data Availability Statement: This study did not perform any data.

Conflicts of Interest: The authors declare no conflict of interest.

\section{References}

1. Centers for Disease Control and Prevention, U.S. Department of Health and Human Services. Surveillance Report of Traumatic Brain Injury-Related Hospitalizations and Death by Agre Group, Sex, and Mechanism of Injury-United States, 2016 and 2017; Centers for Disease Control and Prevention, U.S. Department of Health and Human Services: Atlanta, GA, USA, 2021.

2. Kowalski, R.G.; Hammond, F.M.; Weintraub, A.H.; Nakase-Richardson, R.; Zafonte, R.D.; Whyte, J.; Giacino, J.T. Recovery of Consciousness and Functional Outcome in Moderate and Severe Traumatic Brain Injury. JAMA Neurol. 2021, 78, 548-557. [CrossRef]

3. Hammond, F.M.; Giacino, J.T.; Nakase Richardson, R.; Sherer, M.; Zafonte, R.D.; Whyte, J.; Arciniegas, D.B.; Tang, X. Disorders of Consciousness due to Traumatic Brain Injury: Functional Status Ten Years Post-Injury. J. Neurotrauma 2019, 36, 1136-1146. [CrossRef]

4. Giacino, J.T.; Kalmar, K.; Whyte, J. The JFK Coma Recovery Scale-Revised: Measurement characteristics and diagnostic utility. Arch. Phys. Med. Rehabil. 2004, 85, 2020-2029. [CrossRef]

5. The Multi-Society Task Force on PVS. Medical aspects of the persistent vegetative state (2). N. Engl. J. Med. 1994, 330, 1572-1579. [CrossRef]

6. The Multi-Society Task Force on PVS. Medical aspects of the persistent vegetative state (1). N. Engl. J. Med. 1994, 330, 1499-1508. [CrossRef]

7. Ashwal, S.; Cranford, R. Medical aspects of the persistent vegetative state-a correction. The Multi-Society Task Force on PVS. New Engl. J. Med. 1995, 333, 130. [CrossRef]

8. Lucca, L.F.; Lofaro, D.; Pignolo, L.; Leto, E.; Ursino, M.; Cortese, M.D.; Conforti, D.; Tonin, P.; Cerasa, A. Outcome prediction in disorders of consciousness: The role of coma recovery scale revised. BMC Neurol. 2019, 19, 68. [CrossRef]

9. Lammi, M.H.; Smith, V.H.; Tate, R.L.; Taylor, C.M. The minimally conscious state and recovery potential: A follow-up study 2 to 5 years after traumatic brain injury. Arch. Phys. Med. Rehabil. 2005, 86, 746-754. [CrossRef]

10. Cabrera, L.Y.; Illes, J. Balancing ethics and care in disorders of consciousness. Lancet Neurol. 2018, 17, 112-113. [CrossRef]

11. Martens, G.; Bodien, Y.; Sheau, K.; Christoforou, A.; Giacino, J.T. Which behaviours are first to emerge during recovery of consciousness after severe brain injury? Ann. Phys. Rehabil Med. 2020, 63, 263-269. [CrossRef]

12. Cloninger, C.R. Evolution of human brain functions: The functional structure of human consciousness. Aust. N. Z. J. Psychiatry 2009, 43, 994-1006. [CrossRef]

13. Morsella, E.; Godwin, C.A.; Jantz, T.K.; Krieger, S.C.; Gazzaley, A. Homing in on consciousness in the nervous system: An action-based synthesis. Behav. Brain Sci. 2016, 39, e168. [CrossRef] [PubMed]

14. Edlow, B.L.; Takahashi, E.; Wu, O.; Benner, T.; Dai, G.; Bu, L.; Grant, P.E.; Greer, D.M.; Greenberg, S.M.; Kinney, H.C.; et al. Neuroanatomic connectivity of the human ascending arousal system critical to consciousness and its disorders. J. Neuropathol. Exp. Neurol. 2012, 71, 531-546. [CrossRef] 
15. Schiff, N.D. Recovery of consciousness after severe brain injury: The role of arousal regulation mechanisms and some speculation on the heart-brain interface. Cleve Clin. J. Med. 2010, 77 (Suppl. 3), S27-S33. [CrossRef] [PubMed]

16. Schiff, N.D. Recovery of consciousness after brain injury: A mesocircuit hypothesis. Trends Neurosci. 2010, 33, 1-9. [CrossRef]

17. Cotterill, R.M. Cooperation of the basal ganglia, cerebellum, sensory cerebrum and hippocampus: Possible implications for cognition, consciousness, intelligence and creativity. Prog. Neurobiol. 2001, 64, 1-33. [CrossRef]

18. Malone, C.; Erler, K.S.; Giacino, J.T.; Hammond, F.M.; Juengst, S.B.; Locascio, J.J.; Nakase-Richardson, R.; Verduzco-Gutierrez, M.; Whyte, J.; Zasler, N.; et al. Participation Following Inpatient Rehabilitation for Traumatic Disorders of Consciousness: A TBI Model Systems Study. Front. Neurol. 2019, 10, 1314. [CrossRef]

19. Bodien, Y.G.; Giacino, J.T.; Edlow, B.L. Functional MRI Motor Imagery Tasks to Detect Command Following in Traumatic Disorders of Consciousness. Front. Neurol. 2017, 8, 688. [CrossRef] [PubMed]

20. Giacino, J.T.; Katz, D.I.; Whyte, J. Neurorehabilitation in disorders of consciousness. Semin. Neurol. 2013, 33, 142-156. [CrossRef] [PubMed]

21. Williamson, T.; Ryser, M.D.; Ubel, P.A.; Abdelgadir, J.; Spears, C.A.; Liu, B.; Komisarow, J.; Lemmon, M.E.; Elsamadicy, A.; Lad, S.P. Withdrawal of Life-supporting Treatment in Severe Traumatic Brain Injury. JAMA Surg. 2020, 155, 723-731. [CrossRef]

22. Chaturvedi, J.; Mudgal, S.K.; Venkataram, T.; Gupta, P.; Goyal, N.; Jain, G.; Sharma, A.K.; Sharma, S.K.; Bendok, B.R. Coma recovery scale: Key clinical tool ignored enough in disorders of consciousness. Surg. Neurol. Int. 2021, 12, 93. [CrossRef]

23. Alcock, S.; Batoo, D.; Ande, S.R.; Grierson, R.; Essig, M.; Martin, D.; Trivedi, A.; Sinha, N.; Leeies, M.; Zeiler, F.A.; et al. Early diagnosis of mortality using admission CT perfusion in severe traumatic brain injury patients (ACT-TBI): Protocol for a prospective cohort study. BMJ Open 2021, 11, e047305. [CrossRef]

24. Machado, C.; Perez-Nellar, J.; Estevez, M.; Gonzalez, E. Evidence-based guideline update: Determining brain death in adults: Report of the Quality Standards Subcommittee of the American Academy of Neurology. Neurology 2011, 76, 307, author reply 308-309. [CrossRef] [PubMed]

25. Wijdicks, E.F.; Varelas, P.N.; Gronseth, G.S.; Greer, D.M. Evidence-based guideline update: Determining brain death in adults: Report of the Quality Standards Subcommittee of the American Academy of Neurology. Neurology 2010, 74, 1911-1918. [CrossRef] [PubMed]

26. Teasdale, G.; Jennett, B. Assessment of coma and impaired consciousness. A practical scale. Lancet 1974, 2, 81-84. [CrossRef]

27. Giacino, J.T.; Katz, D.I.; Schiff, N.D.; Whyte, J.; Ashman, E.J.; Ashwal, S.; Barbano, R.; Hammond, F.M.; Laureys, S.; Ling, G.S.F.; et al. Comprehensive Systematic Review Update Summary: Disorders of Consciousness: Report of the Guideline Development, Dissemination, and Implementation Subcommittee of the American Academy of Neurology; the American Congress of Rehabilitation Medicine; and the National Institute on Disability, Independent Living, and Rehabilitation Research. Arch. Phys. Med. Rehabil. 2018, 99, 1710-1719. [CrossRef]

28. Thibaut, A.; Panda, R.; Annen, J.; Sanz, L.R.D.; Naccache, L.; Martial, C.; Chatelle, C.; Aubinet, C.; Bonin, E.A.C.; Barra, A.; et al. Preservation of Brain Activity in Unresponsive Patients Identifies MCS Star. Ann. Neurol. 2021, 90, 89-100. [CrossRef]

29. Thibaut, A.; Bodien, Y.G.; Laureys, S.; Giacino, J.T. Minimally conscious state "plus": Diagnostic criteria and relation to functional recovery. J. Neurol. 2020, 267, 1245-1254. [CrossRef]

30. Bruno, M.A.; Majerus, S.; Boly, M.; Vanhaudenhuyse, A.; Schnakers, C.; Gosseries, O.; Boveroux, P.; Kirsch, M.; Demertzi, A.; Bernard, C.; et al. Functional neuroanatomy underlying the clinical subcategorization of minimally conscious state patients. $J$. Neurol. 2012, 259, 1087-1098. [CrossRef]

31. Sanz, L.R.D.; Thibaut, A.; Edlow, B.L.; Laureys, S.; Gosseries, O. Update on neuroimaging in disorders of consciousness. Curr. Opin. Neurol. 2021, 34, 488-496. [CrossRef]

32. Jang, S.H.; Kwon, Y.H. The relationship between consciousness and the ascending reticular activating system in patients with traumatic brain injury. BMC Neurol. 2020, 20, 375. [CrossRef] [PubMed]

33. Edlow, B.L.; Chatelle, C.; Spencer, C.A.; Chu, C.J.; Bodien, Y.G.; O'Connor, K.L.; Hirschberg, R.E.; Hochberg, L.R.; Giacino, J.T.; Rosenthal, E.S.; et al. Early detection of consciousness in patients with acute severe traumatic brain injury. Brain 2017, 140, 2399-2414. [CrossRef] [PubMed]

34. Chatelle, C.; Rosenthal, E.S.; Bodien, Y.G.; Spencer-Salmon, C.A.; Giacino, J.T.; Edlow, B.L. EEG Correlates of Language Function in Traumatic Disorders of Consciousness. Neurocrit. Care 2020, 33, 449-457. [CrossRef]

35. Scarpino, M.; Lolli, F.; Hakiki, B.; Lanzo, G.; Sterpu, R.; Atzori, T.; Portaccio, E.; Draghi, F.; Amantini, A.; Grippo, A.; et al. EEG and Coma Recovery Scale-Revised prediction of neurological outcome in Disorder of Consciousness patients. Acta Neurol. Scand. 2020, 142, 221-228. [CrossRef]

36. Stender, J.; Gosseries, O.; Bruno, M.A.; Charland-Verville, V.; Vanhaudenhuyse, A.; Demertzi, A.; Chatelle, C.; Thonnard, M.; Thibaut, A.; Heine, L.; et al. Diagnostic precision of PET imaging and functional MRI in disorders of consciousness: A clinical validation study. Lancet 2014, 384, 514-522. [CrossRef]

37. Seel, R.T.; Sherer, M.; Whyte, J.; Katz, D.I.; Giacino, J.T.; Rosenbaum, A.M.; Hammond, F.M.; Kalmar, K.; Pape, T.L.; Zafonte, R.; et al. Assessment scales for disorders of consciousness: Evidence-based recommendations for clinical practice and research. Arch. Phys. Med. Rehabil. 2010, 91, 1795-1813. [CrossRef]

38. Sattin, D.; Minati, L.; Rossi, D.; Covelli, V.; Giovannetti, A.M.; Rosazza, C.; Bersano, A.; Nigri, A.; Leonardi, M. The Coma Recovery Scale Modified Score: A new scoring system for the Coma Recovery Scale-revised for assessment of patients with disorders of consciousness. Int. J. Rehabil. Res. 2015, 38, 350-356. [CrossRef] 
39. Slomine, B.S.; Suskauer, S.J.; Nicholson, R.; Giacino, J.T. Preliminary validation of the coma recovery scale for pediatrics in typically developing young children. Brain Inj. 2019, 33, 1640-1645. [CrossRef]

40. Cortese, M.D.; Riganello, F.; Arcuri, F.; Pugliese, M.E.; Lucca, L.F.; Dolce, G.; Sannita, W.G. Coma recovery scale-r: Variability in the disorder of consciousness. BMC Neurol. 2015, 15, 186. [CrossRef] [PubMed]

41. Formisano, R.; Contrada, M.; Ferri, G.; Schiattone, S.; Iosa, M.; Aloisi, M. The Glasgow Outcome Scale Extended-Revised (GOSE-R) to include Minimally Conscious State in the Vegetative State/Unresponsive Wakefulness Syndrome category: A correlation with Coma Recovery Scale-Revised (CRS-R). Eur. J. Phys. Rehabil. Med. 2019, 55, 139-140. [CrossRef] [PubMed]

42. Aubinet, C.; Cassol, H.; Bodart, O.; Sanz, L.R.D.; Wannez, S.; Martial, C.; Thibaut, A.; Martens, G.; Carriere, M.; Gosseries, O.; et al. Simplified Evaluation of CONsciousness Disorders (SECONDs) in individuals with severe brain injury: A validation study. Ann. Phys. Rehabil. Med. 2020, S1877-0657, 30160-30163. [CrossRef]

43. Sanz, L.R.D.; Aubinet, C.; Cassol, H.; Bodart, O.; Wannez, S.; Bonin, E.A.C.; Barra, A.; Lejeune, N.; Martial, C.; Chatelle, C.; et al. SECONDs Administration Guidelines: A Fast Tool to Assess Consciousness in Brain-injured Patients. J. Vis. Exp. 2021, 168, e61968. [CrossRef]

44. Rappaport, M.; Hall, K.M.; Hopkins, K.; Belleza, T.; Cope, D.N. Disability rating scale for severe head trauma: Coma to community. Arch. Phys. Med. Rehabil. 1982, 63, 118-123. [PubMed]

45. Varjabic, M.; Bakran, Z.; Tusek, S.; Bujisic, G. Assessment of long-term activity limitations and participation restrictions of persons with traumatic brain injury using the disability rating scale. Coll Antropol 2010, 34 (Suppl. 1), 157-164.

46. Kelsen, J.; Karlsson, M.; Hansson, M.J.; Yang, Z.; Fischer, W.; Hugerth, M.; Nordstrom, C.H.; Astrand, R.; Keep, M.F.; Kilbaugh, T.; et al. Copenhagen Head Injury Ciclosporin Study: A Phase Ila Safety, Pharmacokinetics, and Biomarker Study of Ciclosporin in Severe Traumatic Brain Injury Patients. J. Neurotrauma 2019, 36, 3253-3263. [CrossRef]

47. Giacino, J.T.; Whyte, J. Amantadine to improve neurorecovery in traumatic brain injury-associated diffuse axonal injury: A pilot double-blind randomized trial. J. Head Trauma Rehabil 2003, 18, 4-5, author reply 5-6. [CrossRef]

48. Giacino, J.T.; Whyte, J.; Bagiella, E.; Kalmar, K.; Childs, N.; Khademi, A.; Eifert, B.; Long, D.; Katz, D.I.; Cho, S.; et al. Placebocontrolled trial of amantadine for severe traumatic brain injury. N. Engl. J. Med. 2012, 366, 819-826. [CrossRef]

49. Alkhachroum, A.; Eliseyev, A.; Der-Nigoghossian, C.A.; Rubinos, C.; Kromm, J.A.; Mathews, E.; Bauerschmidt, A.; Doyle, K.; Velasquez, A.; Egbebike, J.A.; et al. EEG to detect early recovery of consciousness in amantadine-treated acute brain injury patients. J. Neurol. Neurosurg. Psychiatry 2020, 91, 675-676. [CrossRef]

50. Ghalaenovi, H.; Fattahi, A.; Koohpayehzadeh, J.; Khodadost, M.; Fatahi, N.; Taheri, M.; Azimi, A.; Rohani, S.; Rahatlou, H. The effects of amantadine on traumatic brain injury outcome: A double-blind, randomized, controlled, clinical trial. Brain Inj. 2018, 32, 1050-1055. [CrossRef]

51. Hughes, S.; Colantonio, A.; Santaguida, P.L.; Paton, T. Amantadine to enhance readiness for rehabilitation following severe traumatic brain injury. Brain Inj. 2005, 19, 1197-1206. [CrossRef]

52. Fridman, E.A.; Calvar, J.; Bonetto, M.; Gamzu, E.; Krimchansky, B.Z.; Meli, F.; Leiguarda, R.C.; Zafonte, R. Fast awakening from minimally conscious state with apomorphine. Brain Inj. 2009, 23, 172-177. [CrossRef] [PubMed]

53. Fridman, E.A.; Krimchansky, B.Z.; Bonetto, M.; Galperin, T.; Gamzu, E.R.; Leiguarda, R.C.; Zafonte, R. Continuous subcutaneous apomorphine for severe disorders of consciousness after traumatic brain injury. Brain Inj. 2010, 24, 636-641. [CrossRef] [PubMed]

54. Sanz, L.R.D.; Lejeune, N.; Blandiaux, S.; Bonin, E.; Thibaut, A.; Stender, J.; Farber, N.M.; Zafonte, R.D.; Schiff, N.D.; Laureys, S.; et al. Treating Disorders of Consciousness with Apomorphine: Protocol for a Double-Blind Randomized Controlled Trial Using Multimodal Assessments. Front. Neurol. 2019, 10, 248. [CrossRef] [PubMed]

55. Clauss, R.P.; Guldenpfennig, W.M.; Nel, H.W.; Sathekge, M.M.; Venkannagari, R.R. Extraordinary arousal from semi-comatose state on zolpidem. A case report. S. Afr. Med. J. 2000, 90, 68-72. [PubMed]

56. Bomalaski, M.N.; Claflin, E.S.; Townsend, W.; Peterson, M.D. Zolpidem for the Treatment of Neurologic Disorders: A Systematic Review. JAMA Neurol. 2017, 74, 1130-1139. [CrossRef]

57. Williams, S.T.; Conte, M.M.; Goldfine, A.M.; Noirhomme, Q.; Gosseries, O.; Thonnard, M.; Beattie, B.; Hersh, J.; Katz, D.I.; Victor, J.D.; et al. Common resting brain dynamics indicate a possible mechanism underlying zolpidem response in severe brain injury. eLife 2013, 2, e01157. [CrossRef]

58. Thonnard, M.; Gosseries, O.; Demertzi, A.; Lugo, Z.; Vanhaudenhuyse, A.; Bruno, M.A.; Chatelle, C.; Thibaut, A.; Charland-Verville, V.; Habbal, D.; et al. Effect of zolpidem in chronic disorders of consciousness: A prospective openlabel study. Funct. Neurol. 2013, 28, 259-264. [CrossRef]

59. Sripad, P.; Rosenberg, J.; Boers, F.; Filss, C.P.; Galldiks, N.; Langen, K.J.; Clauss, R.; Shah, N.J.; Dammers, J. Effect of Zolpidem in the Aftermath of Traumatic Brain Injury: An MEG Study. Case Rep. Neurol. Med. 2020, 2020, 8597062. [CrossRef]

60. Khalili, H.; Rakhsha, A.; Ghaedian, T.; Niakan, A.; Masoudi, N. Application of Brain Perfusion SPECT in the Evaluation of Response to Zolpidem Therapy in Consciousness Disorder Due to Traumatic Brain Injury. Indian J. Nucl. Med. 2020, 35, 315-320. [CrossRef]

61. Zhang, B.; O’Brien, K.; Won, W.; Li, S. A Retrospective Analysis on Clinical Practice-Based Approaches Using Zolpidem and Lorazepam in Disorders of Consciousness. Brain Sci. 2021, 11, 726. [CrossRef]

62. Long, Y.; Li, J.; Yang, F.; Wang, J.; Wang, X. Wearable and Implantable Electroceuticals for Therapeutic Electrostimulations. Adv. Sci. 2021, 8, 2004023. [CrossRef]

63. Mishra, S. Electroceuticals in medicine-The brave new future. Indian Heart J. 2017, 69, 685-686. [CrossRef] 
64. Johnson, R.L.; Wilson, C.G. A review of vagus nerve stimulation as a therapeutic intervention. J. Inflamm. Res. 2018, 11, 203-213. [CrossRef] [PubMed]

65. Goyal, A.; Goetz, S.; Stanslaski, S.; Oh, Y.; Rusheen, A.E.; Klassen, B.; Miller, K.; Blaha, C.D.; Bennet, K.E.; Lee, K. The development of an implantable deep brain stimulation device with simultaneous chronic electrophysiological recording and stimulation in humans. Biosens. Bioelectron. 2021, 176, 112888. [CrossRef]

66. McLardy, T.; Ervin, F.; Mark, V.; Scoville, W.; Sweet, W. Attempted inset-electrodes-arousal from traumatic coma: Neuropathological findings. Trans. Am. Neurol. Assoc. 1968, 93, 25-30. [PubMed]

67. Bourdillon, P.; Hermann, B.; Sitt, J.D.; Naccache, L. Electromagnetic Brain Stimulation in Patients With Disorders of Consciousness. Front. Neurosci. 2019, 13, 223. [CrossRef]

68. Angelakis, E.; Liouta, E.; Andreadis, N.; Korfias, S.; Ktonas, P.; Stranjalis, G.; Sakas, D.E. Transcranial direct current stimulation effects in disorders of consciousness. Arch. Phys. Med. Rehabil. 2014, 95, 283-289. [CrossRef] [PubMed]

69. Thibaut, A.; Bruno, M.A.; Ledoux, D.; Demertzi, A.; Laureys, S. tDCS in patients with disorders of consciousness: Sham-controlled randomized double-blind study. Neurology 2014, 82, 1112-1118. [CrossRef]

70. Thibaut, A.; Di Perri, C.; Chatelle, C.; Bruno, M.A.; Bahri, M.A.; Wannez, S.; Piarulli, A.; Bernard, C.; Martial, C.; Heine, L.; et al. Clinical Response to tDCS Depends on Residual Brain Metabolism and Grey Matter Integrity in Patients With Minimally Conscious State. Brain Stimul. 2015, 8, 1116-1123. [CrossRef]

71. Martens, G.; Fregni, F.; Carriere, M.; Barra, A.; Laureys, S.; Thibaut, A. Single tDCS session of motor cortex in patients with disorders of consciousness: A pilot study. Brain Inj. 2019, 33, 1679-1683. [CrossRef]

72. Zaninotto, A.L.; El-Hagrassy, M.M.; Green, J.R.; Babo, M.; Paglioni, V.M.; Benute, G.G.; Paiva, W.S. Transcranial direct current stimulation (tDCS) effects on traumatic brain injury (TBI) recovery: A systematic review. Dement. Neuropsychol. 2019, 13, 172-179. [CrossRef] [PubMed]

73. Casali, A.G.; Gosseries, O.; Rosanova, M.; Boly, M.; Sarasso, S.; Casali, K.R.; Casarotto, S.; Bruno, M.A.; Laureys, S.; Tononi, G.; et al. A theoretically based index of consciousness independent of sensory processing and behavior. Sci. Transl. Med. 2013, 5, 198ra105. [CrossRef]

74. Louise-Bender Pape, T.; Rosenow, J.; Lewis, G.; Ahmed, G.; Walker, M.; Guernon, A.; Roth, H.; Patil, V. Repetitive transcranial magnetic stimulation-associated neurobehavioral gains during coma recovery. Brain Stimul. 2009, 2, 22-35. [CrossRef]

75. Bender Pape, T.L.; Herrold, A.A.; Livengood, S.L.; Guernon, A.; Weaver, J.A.; Higgins, J.P.; Rosenow, J.M.; Walsh, E.; Bhaumik, R.; Pacheco, M.; et al. A Pilot Trial Examining the Merits of Combining Amantadine and Repetitive Transcranial Magnetic Stimulation as an Intervention for Persons with Disordered Consciousness After TBI. J. Head Trauma Rehabil. 2020, 35, 371-387. [CrossRef]

76. Pink, A.E.; Williams, C.; Alderman, N.; Stoffels, M. The use of repetitive transcranial magnetic stimulation (rTMS) following traumatic brain injury (TBI): A scoping review. Neuropsychol. Rehabil. 2021, 31, 479-505. [CrossRef]

77. Zewdie, E.; Ciechanski, P.; Kuo, H.C.; Giuffre, A.; Kahl, C.; King, R.; Cole, L.; Godfrey, H.; Seeger, T.; Swansburg, R.; et al. Safety and tolerability of transcranial magnetic and direct current stimulation in children: Prospective single center evidence from 3.5 million stimulations. Brain Stimul. 2020, 13, 565-575. [CrossRef] [PubMed]

78. Corazzol, M.; Lio, G.; Lefevre, A.; Deiana, G.; Tell, L.; Andre-Obadia, N.; Bourdillon, P.; Guenot, M.; Desmurget, M.; Luaute, J.; et al. Restoring consciousness with vagus nerve stimulation. Curr. Biol. 2017, 27, R994-R996. [CrossRef]

79. Hakon, J.; Moghiseh, M.; Poulsen, I.; Oland, C.M.L.; Hansen, C.P.; Sabers, A. Transcutaneous Vagus Nerve Stimulation in Patients with Severe Traumatic Brain Injury: A Feasibility Trial. Neuromodulation 2020, 23, 859-864. [CrossRef] [PubMed]

80. Lemaire, J.J.; Sontheimer, A.; Pereira, B.; Coste, J.; Rosenberg, S.; Sarret, C.; Coll, G.; Gabrillargues, J.; Jean, B.; Gillart, T.; et al. Deep brain stimulation in five patients with severe disorders of consciousness. Ann. Clin. Transl. Neurol. 2018, 5, 1372-1384. [CrossRef] [PubMed]

81. Rezaei Haddad, A.; Lythe, V.; Green, A.L. Deep Brain Stimulation for Recovery of Consciousness in Minimally Conscious Patients After Traumatic Brain Injury: A Systematic Review. Neuromodulation 2019, 22, 373-379. [CrossRef] [PubMed]

82. Vanhoecke, J.; Hariz, M. Deep brain stimulation for disorders of consciousness: Systematic review of cases and ethics. Brain Stimul. 2017, 10, 1013-1023. [CrossRef]

83. Maxwell, W.L.; MacKinnon, M.A.; Smith, D.H.; McIntosh, T.K.; Graham, D.I. Thalamic nuclei after human blunt head injury. J. Neuropathol. Exp. Neurol. 2006, 65, 478-488. [CrossRef] [PubMed]

84. Schiff, N.D.; Plum, F. The role of arousal and "gating" systems in the neurology of impaired consciousness. J. Clin. Neurophysiol. 2000, 17, 438-452. [CrossRef]

85. Schiff, N.D. Central thalamic contributions to arousal regulation and neurological disorders of consciousness. Ann. N. Y. Acad. Sci. 2008, 1129, 105-118. [CrossRef]

86. Lacey, C.J.; Bolam, J.P.; Magill, P.J. Novel and distinct operational principles of intralaminar thalamic neurons and their striatal projections. J. Neurosci. 2007, 27, 4374-4384. [CrossRef] [PubMed]

87. Witzig, V.S.; Komnig, D.; Falkenburger, B.H. Changes in Striatal Medium Spiny Neuron Morphology Resulting from Dopamine Depletion Are Reversible. Cells 2020, 9, 2441. [CrossRef] [PubMed]

88. Gerfen, C.R.; Surmeier, D.J. Modulation of striatal projection systems by dopamine. Annu. Rev. Neurosci. 2011, 34, 441-466. [CrossRef] 